\title{
DEVELOPMENT AND IN VITRO-IN VIVO EVALUATION OF GASTRORETENTIVE FLOATING TABLETS OF AN ANTIRETROVIRAL AGENT RITONAVIR
}

\section{SHIREESH KIRAN R ${ }^{1 *}$, CHANDRA SHEKAR B ${ }^{2}$, NAGENDRA BABU B ${ }^{3}$}

\begin{abstract}
${ }^{1}$ Department of Pharmaceutics, CMR College of Pharmacy, Kandlakoya, Medchal - 501401, Hyderabad, Telangana, India. ${ }^{2}$ Department of Pharmaceutics, St. Pauls College of Pharmacy, Turkayamjal (V), Hyderabad - 501510, Telangana, India. ${ }^{3}$ Department of Pharmaceutics, Council of Scientific and Industrial Research-Indian Institute of Chemical Technology, Tarnaka, Hyderabad - 500007, Telangana, India. Email: shireeshr@gmail.com
\end{abstract}

Received: 18 August 2018, Revised and Accepted: 12 November 2018

\section{ABSTRACT}

Objective: The present research work concerns the development of the extended release of Ritonavir floating matrix tablets, designed to prolong the gastric residence time, increase the drug bioavailability, and diminish the side effects of irritating drugs.

Methods: The floating tablets of Ritonavir were prepared by direct compression method using different grades of hydroxypropyl methylcellulose (HPMC), crospovidone, Polyox WSR 303, and sodium bicarbonate, as gas generating agent. Evaluation parameters and in vivo radiographic studies were conducted in suitable model.

Results: Among all formulations, F21 was chosen as optimized formulation based on evaluation parameters such as floating lag time (33 s), total floating time $(>24 \mathrm{~h})$, and in vitro dissolution studies. From in vitro dissolution studies, the optimized formulation F21 and marketed product were shown $98.67 \%$ and $91.46 \pm 5.02 \%$ of drug release, respectively. The main appliance of medication discharge follows zero-order kinetics and nonFickian transport by coupled diffusion and erosion. In vivo experiments maintained the potentials in extending the gastric residence time in the fasted state in beagle dogs. The mean gastric residence time of the optimized formulation found to be $330 \min \pm 40$ in the stomach, where longer gastric residence time is an important condition for prolonged or controlled drug release and also for enhanced bioavailability.

Conclusion: From in vitro and in vivo radiographic studies, Ritonavir floating tablets estimated to provide novel choice for harmless, inexpensive, and extended release for the effective management of AIDS.

Keywords: Ritonavir AIDS, Floating tablets, Hydroxypropyl methylcellulose, Radiographic studies.

(c) 2019 The Authors. Published by Innovare Academic Sciences Pvt Ltd. This is an open access article under the CC BY license (http://creativecommons. org/licenses/by/4. 0/) DOI: http://dx.doi.org/10.22159/ajpcr.2019.v12i2.29196

\section{INTRODUCTION}

Oral route is foremost common route of administering the drug due to the ease of formulation, low-cost, convenient for the patient, and simple regulatory approval process. Based on the requirement, formulations can be changed from immediate release to extended release using several polymers [1]. Gastroretentive drug delivery systems can valuable in the transport of medications that remain mainly engrossed in the duodenum and upper jejunum/those that need an absorption window in the gastrointestinal tract [2]. Gastroretentive floating dosage forms remain constantly researched and advanced stomach is a main absorption zone [3]. In accumulation, relatively brief gastric emptying time in humans, through the stomach/upper part of the intestine (major absorption zone), can result in incomplete medication release from drug delivery system, leading to reduced generally ability drug. Some drugs like Ritonavir demonstrates region-specific absorption in different regions of the intestine because of different $\mathrm{pH}$ conditions, various enzymes and endogenous constituents like bile [4].

There exist numerous methodologies toward target an exact site sustained/controlled release fashion [5]. Some common methodologies used toward increased gastric residence time of pharmaceutical dosage forms include floating systems, swelling and expanding systems, bioadhesive systems, unfolding and modified shape systems, and highdensity systems. Floating drug delivery systems have bulk density (BD) lower than gastric fluids and so remain buoyant in the stomach without distressing gastric emptying rate for a prolonged period of time [6]. While system remains afloat, drug released the desired rate from system [7]. Following drug release, residual system gets emptied from the stomach.
However, besides a minimal gastric content needed to allow proper achievement buoyancy retention principle, minimal equal of floating force is also required keep dosage form reliably buoyant on surface meal [8].

\section{MATERIALS AND METHODS}

Materials

Ritonavir was procured from MSN Labs Ltd., Hyderabad. Hydroxypropyl methylcellulose (HPMC) K4M, HPMC K15M, HPMC K100M, and Polyox WSR 303 existed were obtained from Granules India Ltd., Hyderabad. Sodium bicarbonate, citric acid, PVP K 30 , talc, and magnesium stearate existed were procured from S D Fine-Chem Ltd., Mumbai, and all other chemicals used existed were of analytical grade.

\section{Methods}

Micromeritic properties of final blend

Final blend of all preparations was evaluated for BD, tapped density (TD), compressibility index (CI), Hausner ratio, and angle of repose [9].

\section{Formulation method}

Accurately weighed amounts of polymers were in a mortar and mixed geometrically, and the required quantity of Ritonavir was added to the polymers. Sodium bicarbonate was taken separately, and the powder passed through sieve no 40 . The whole mixture was collected in a plastic bag and mixed for $3 \mathrm{~min}$. Magnesium stearate added and mixed for $5 \mathrm{~min}$, and later, Talc was added and mixed for 2 min [10-12]. The mixture equivalent to $300 \mathrm{mg}$ was compressed into tablets with $10 \mathrm{~mm}$ round concave punches, and the composition is shown in Tables 1-3. 
Table 1: Composition of floating matrix tablets of Ritonavir with HPMC K4M

\begin{tabular}{llllllll}
\hline \multirow{2}{*}{ Ingredients (weight in mg) } & \multicolumn{8}{l}{ Formulations } & & & & \\
\cline { 2 - 9 } & F1 & F2 & F3 & F4 & F5 & F6 & F7 \\
\hline Ritonavir & 100 & 100 & 100 & 100 & 100 & 100 & 100 \\
HPMC K4M & 50 & 55 & 60 & 65 & 70 & 75 & 80 \\
Crospovidone & 50 & 50 & 50 & 50 & 40 & 25 & 20 \\
Polyox WSR 303 & 20 & 25 & 30 & 35 & 40 & 45 & 50 \\
Sodium bicarbonate & 20 & 22 & 24 & 26 & 28 & 30 & 32 \\
Citric acid & 10 & 10 & 10 & 10 & 10 & 10 & 10 \\
PVP K-30 & 46 & 34 & 22 & 10 & 8 & 11 & 4 \\
Talc & 2 & 2 & 2 & 2 & 2 & 2 & 2 \\
Magnesium stearate & 2 & 2 & 2 & 2 & 2 & 2 & 2 \\
Total weight & 300 & 300 & 300 & 300 & 300 & 300 & 300 \\
\hline
\end{tabular}

HPMC: Hydroxypropyl methylcellulose

Table 2: Composition of floating matrix tablets of Ritonavir with HPMC K15M

\begin{tabular}{lllllllll}
\hline Ingredients (weight in mg) & \multicolumn{9}{l}{ Formulations } \\
\cline { 2 - 9 } & F8 & F9 & F10 & F11 & F12 & F13 & F14 \\
\hline Ritonavir & 100 & 100 & 100 & 100 & 100 & 100 & 100 \\
HPMC K15M & 50 & 55 & 60 & 65 & 70 & 75 & 80 \\
Crospovidone & 50 & 50 & 50 & 50 & 40 & 25 & 20 \\
Polyox WSR 303 & 20 & 25 & 30 & 35 & 40 & 45 & 50 \\
Sodium bicarbonate & 20 & 22 & 24 & 26 & 28 & 30 & 32 \\
Citric acid & 10 & 10 & 10 & 10 & 10 & 10 & 10 \\
PVP K-30 & 46 & 34 & 22 & 10 & 8 & 11 & 4 \\
Talc & 2 & 2 & 2 & 2 & 2 & 2 & 2 \\
Magnesium stearate & 2 & 2 & 2 & 2 & 2 & 2 & 2 \\
Total weight & 300 & 300 & 300 & 300 & 300 & 300 & 300 \\
\hline
\end{tabular}

HPMC: Hydroxypropyl methylcellulose

Table 3: Composition of floating matrix tablets of Ritonavir with HPMC K100M

Ingredients (weight in mg) Formulations

$\begin{array}{lllllll}\text { F15 } & \text { F16 } & \text { F17 } & \text { F18 } & \text { F19 } & \text { F20 } & \text { F21 }\end{array}$

Ritonavir

HPMC K100M

Crospovidone

Polyox WSR 303

Sodium bicarbonate

Citric acid

PVP K-30

Talc

Magnesium stearate

Total weight

$\begin{array}{lllllll}100 & 100 & 100 & 100 & 100 & 100 & 100\end{array}$

HPMC: Hydroxypropyl methylcellulose

Evaluation of floating matrix tablets of Ritonavir

Parameters such as weight variation, thickness, hardness, and ability were evaluated according to the reported method [13]

\section{In vitro buoyancy studies}

The in vitro buoyancy was determined by floating lag time. The tablets existed placed in a $100 \mathrm{ml}$ beaker containing $0.1 \mathrm{~N}$ hydrochloric acid $(\mathrm{N} \mathrm{HCl})$. Time required for tablet to rise to surface and float was determined as floating lag time [14].

\section{Drug content}

Twenty tablets were taken and powdered. Powder equivalent to one dose each transferred to a $100 \mathrm{ml}$ volumetric flask and $0.1 \mathrm{~N} \mathrm{HCl}$ was added; volume was then made up to mark with $0.1 \mathrm{~N} \mathrm{HCl}$. Solution was filtered and diluted suitably and drug content in samples was estimated using ultraviolet (UV)-spectrophotometer at $238 \mathrm{~nm}$ [15].

\section{In vitro drug release studies}

In vitro drug release study was performed for prepared tablets using USP Type II dissolution apparatus using $900 \mathrm{ml}$ of $0.1 \mathrm{~N} \mathrm{HCl}$ at a temperature of $37 \pm 0.5^{\circ} \mathrm{C}$ at $50 \mathrm{rpm} .5 \mathrm{ml}$ of sample was collected at 0 , $2,4,6,8,12,16,20$, and $24 \mathrm{~h}$ and the same volume of fresh media was replenished. Drug content in samples was estimated using UV visible spectrophotometer at $238 \mathrm{~nm}$ [16]

\section{Release order kinetics Ritonavir tablets}

In vitro release data from several formulations containing Ritonavir were determined kinetically using different mathematical models such as zero-order, first-order, Higuchi, and Korsmeyer-Peppas model [17].

\section{Drug-excipient compatibility studies}

Fourier-transform infrared spectroscopy (FTIR)

The spectral analysis can be used to identify the functional groups in the pure drug and drug-excipient compatibility. Pure Ritonavir FTIR spectra, physical mixtures, and optimized formulation were recorded using FTIR (SHIMADZU) [18].

\section{Differential scanning calorimetry (DSC)}

DSC studies carried out using DSC 60, having TA60 Software, Shimadzu, Japan. DSC thermograms were recorded for pure drug and optimized formulations. Accurately weighed samples were placed on aluminum plate, sealed with aluminum lids, and heated at a constant rate of $5^{\circ} \mathrm{C} / \mathrm{min}$, over a temperature range of $0-250^{\circ} \mathrm{C}$.

\section{Scanning electron microscopy (SEM) studies}

The surface and shape characteristics of pellets were determined by SEM (HITACHI, S-3700N). Photographs were taken and recorded at suitable magnification.

\section{Stability studies}

Stability testing was conducted at $40^{\circ} \mathrm{C} \pm 2^{\circ} \mathrm{C} / 75 \% \mathrm{RH} \pm 5 \% \mathrm{RH} 3$ months using stability chamber (ThermoLab, Mumbai). Samples were withdrawn at predetermined intervals of $0,30,60$, and 90 days' period according to the ICH guidelines [19]. Various in vitro parameters such as percentage yield, entrapment efficiency, and in vitro release studies were evaluated.

\section{Tablet preparation for in vivo radiographic studies}

Ritonavir tablets of $300 \mathrm{mg}$ in weight existed were prepared for in vivo radiographic studies in beagle dogs. To make tablets X-ray opaque incorporation of BaSO4 necessary. For in vivo radiographic studies, $40 \mathrm{mg}$ of Ritonavir and $5 \mathrm{mg}$ of PVP $\mathrm{K} 30$ were replaced with $\mathrm{BaSO}_{4}$ to ensure visibility by X-ray. Amount of X-ray opaque material in these tablets sufficient to ensure visibility by X-ray. Analyses confirmed that these tablets like tablets for in vitro testing, i.e. mechanical strength, floating properties, controlled drug release [20].

\section{Ritonavir in vivo radiographic studies}

Three healthy beagle dogs, weighing approximately $16 \mathrm{~kg}$, existed were used throughout the study. In each experiment, an unanesthetized animal was fasted for $24 \mathrm{~h}$ and first radiograph was made to ensure the absence of radiopaque material in the stomach. Dogs swallowed one of the tablets and immediately afterward drank $100 \mathrm{ml}$ of water. During experiment, dogs were not allowed to eat, but water existed available ad libitum. The study protocol was approved by the institutional animal ethics committee with No. CPCSEA/1657/IAEC/ CMRCP/PhD-15/37. For radiographic imaging, animal was positioned in a right lateral or ventrodorsally recumbency, and after determined time intervals, the radiographs of the abdomen were taken using an X-ray machine (General Electric Corporation, USA). Distance between the source of X-rays and the object was maintained similar for all images [21]. This allowed us to see tablet in the body of the stomach. At different time intervals of $0.5,3,4$, and $6 \mathrm{~h}$ post-administration of tablets, dogs were exposed to abdominal X-ray imaging [22]. 
Table 4: Micromeretic properties of prepared powder blends of Ritonavir

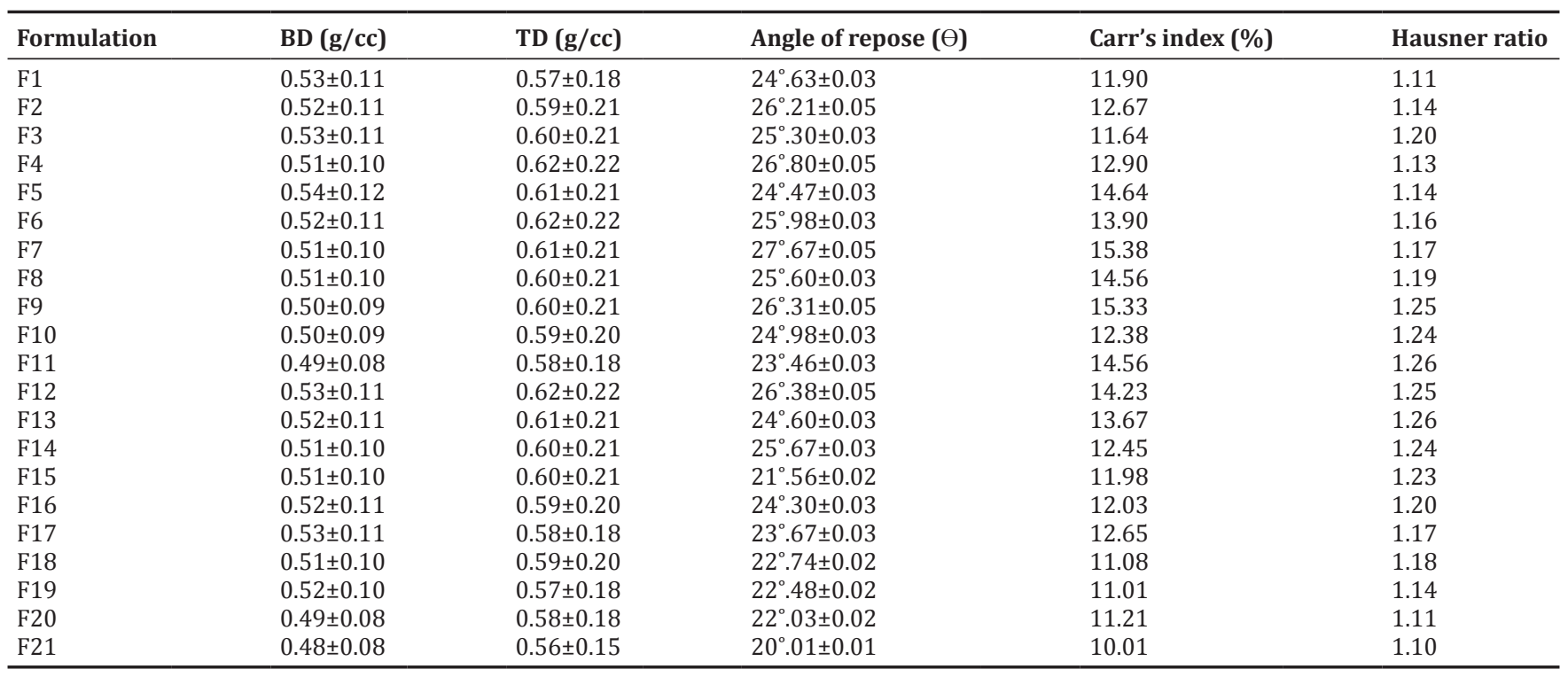

Above parameters are communicated as average \pm standard deviation; (n=3), BD: Bulk density, TD: Tapped density

Table 5: Evaluation parameters of Ritonavir floating tablets

\begin{tabular}{|c|c|c|c|c|c|c|c|}
\hline $\begin{array}{l}\text { Formulation } \\
\text { number }\end{array}$ & $\begin{array}{l}{ }^{*} \text { Weight } \\
\text { variation }(\mathrm{mg})\end{array}$ & \#Thickness (mm) & \#Hardness $\left(\mathrm{Kg} / \mathrm{Cm}^{2}\right)$ & \#Friability (\%) & $\begin{array}{l}\text { \#Content } \\
\text { uniformity (\%) }\end{array}$ & $\begin{array}{l}\text { Floating lag } \\
\text { time (s) }\end{array}$ & $\begin{array}{l}\text { Total floating } \\
\text { time (h) }\end{array}$ \\
\hline F1 & $297 \pm 0.8$ & $3.21 \pm 0.18$ & $4.6 \pm 0.46$ & 0.22 & $96.31 \pm 0.45$ & 48 & $>24$ \\
\hline $\mathrm{F} 2$ & $298 \pm 0.8$ & $3.54 \pm 0.27$ & $4.8 \pm 0.48$ & 0.23 & $95.21 \pm 0.35$ & 45 & $>24$ \\
\hline F3 & $299 \pm 0.9$ & $3.46 \pm 0.22$ & $5.6 \pm 0.53$ & 0.28 & $94.20 \pm 0.35$ & 42 & $>24$ \\
\hline F4 & $298 \pm 0.8$ & $3.81 \pm 0.30$ & $5.1 \pm 0.50$ & 0.26 & $96.13 \pm 0.45$ & 40 & $>24$ \\
\hline F5 & $299 \pm 0.9$ & $3.90 \pm 0.38$ & $4.9 \pm 0.48$ & 0.24 & $95.12 \pm 0.35$ & 38 & $>24$ \\
\hline F6 & $300 \pm 0.10$ & $3.85 \pm 0.36$ & $4.7 \pm 0.46$ & 0.23 & $94.23 \pm 0.35$ & 35 & $>24$ \\
\hline F8 & $299 \pm 0.9$ & $3.98 \pm 0.45$ & $4.8 \pm 0.48$ & 0.22 & $94.65 \pm 0.35$ & 46 & $>24$ \\
\hline F9 & $301 \pm 0.5$ & $3.67 \pm 0.32$ & $4.7 \pm 0.46$ & 0.19 & $96.31 \pm 0.45$ & 44 & $>24$ \\
\hline F10 & $300 \pm 0.5$ & $3.35 \pm 0.18$ & $4.9 \pm 0.48$ & 0.18 & $90.24 \pm 0.15$ & 41 & $>24$ \\
\hline F11 & $297 \pm 0.8$ & $3.29 \pm 0.15$ & $4.8 \pm 0.48$ & 0.21 & $97.23 \pm 0.60$ & 39 & $>24$ \\
\hline F12 & $299 \pm 0.8$ & $3.38 \pm 0.18$ & $4.6 \pm 0.46$ & 0.23 & $95.61 \pm 0.35$ & 37 & $>24$ \\
\hline F13 & $300 \pm 0.10$ & $3.40 \pm 0.21$ & $4.8 \pm 0.48$ & 0.25 & $94.28 \pm 0.35$ & 36 & $>24$ \\
\hline F14 & $298 \pm 0.8$ & $3.28 \pm 0.15$ & $4.9 \pm 0.48$ & 0.26 & $93.46 \pm 0.19$ & 35 & $>24$ \\
\hline F15 & $297 \pm 0.8$ & $3.35 \pm 0.18$ & $5.5 \pm 0.43$ & 0.28 & $92.15 \pm 0.19$ & 47 & $>24$ \\
\hline F17 & $300 \pm 0.10$ & $3.18 \pm 0.09$ & $5.0 \pm 0.49$ & 0.25 & $91.26 \pm 0.18$ & 43 & $>24$ \\
\hline F18 & $298 \pm 0.8$ & $3.20 \pm 0.18$ & $4.9 \pm 0.48$ & 0.20 & $90.74 \pm 0.20$ & 40 & $>24$ \\
\hline F19 & $300 \pm 0.8$ & $3.42 \pm 0.20$ & $4.7 \pm 0.46$ & 0.19 & $94.67 \pm 0.35$ & 38 & $>24$ \\
\hline F20 & $299 \pm 0.9$ & $3.23 \pm 0.15$ & $4.9 \pm 0.48$ & 0.18 & $96.12 \pm 0.45$ & 36 & $>24$ \\
\hline F21 & $302 \pm 0.10$ & $3.11 \pm 0.08$ & $4.5 \pm 0.45$ & 0.15 & $98.36 \pm 0.68$ & 33 & $>24$ \\
\hline
\end{tabular}

*Values are expressed in mean \pm SD: $(n=20)$ \#Values are expressed in mean \pm SD: $(n=3)$

\section{RESULTS AND DISCUSSION}

Micromeritic properties of prepared powder blend Ritonavir The results of BD formulations bearing F1 to F21 were reported in the range of $0.48 \pm 0.08 \mathrm{~g} / \mathrm{cc}-0.54 \pm 0.12 \mathrm{~g} / \mathrm{cc}$. The findings of TD formulations F1 to F21 were reported in the range of $0.56 \pm 0.15 \mathrm{~g} / \mathrm{cc}-0.62 \pm 0.22 \mathrm{~g} / \mathrm{cc}$. The angle of repose of all the formulations was found to be satisfactory. The formulation F21 was having an angle of repose value of $20.01 \pm 0.01$, and CI values existed found to be in range of 10.01-15.38\%. These findings indicated that all batches of formulations exhibited good flow properties. Hausner's ratio values were in the range of $1.10-1.26 \%$ and values are shown in Table 4.

\section{Physicochemical properties of Ritonavir floating tablets}

The Ritonavir floating tablets were prepared, and the compositions of different formulations existed are shown in Tables 1-3 and the tablets are shown in Fig 1.

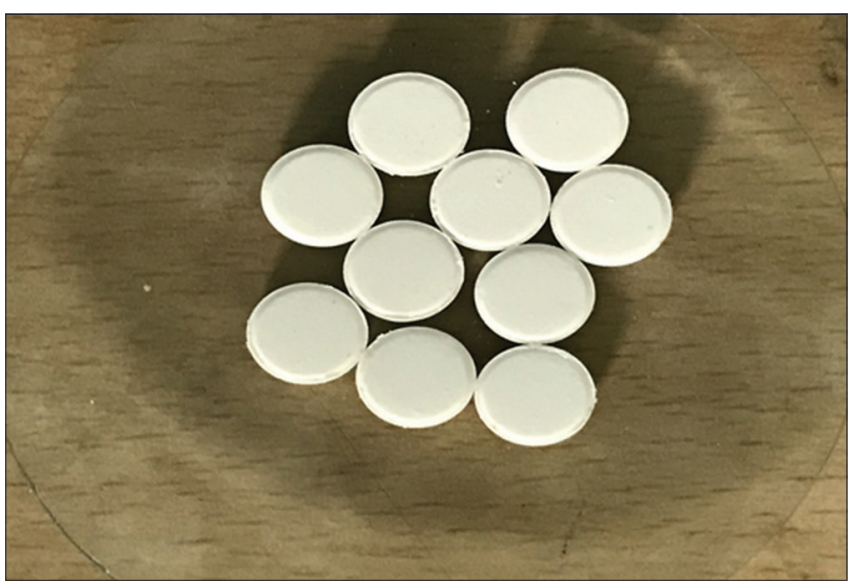

Figure 1: Ritonavir floating tablets 
Table 6: Release order kinetics of F21 and marketed product

\begin{tabular}{|c|c|c|c|c|c|}
\hline Formulation code & Zero order & First order & Higuchi & Korsmeyer-Peppas & $\mathbf{n}$ \\
\hline F1 & 0.9798 & 0.8081 & 0.933 & 0.892 & 0.76 \\
\hline $\mathrm{F} 2$ & 0.968 & 0.7063 & 0.932 & 0.911 & 0.709 \\
\hline F3 & 0.9704 & 0.7353 & 0.916 & 0.927 & 0.77 \\
\hline F4 & 0.9783 & 0.7142 & 0.9597 & 0.921 & 0.795 \\
\hline F5 & 0.9329 & 0.6417 & 0.957 & 0.856 & 0.773 \\
\hline F6 & 0.9354 & 0.7068 & 0.9557 & 0.8617 & 0.702 \\
\hline F7 & 0.9399 & 0.6355 & 0.9603 & 0.8993 & 0.658 \\
\hline F9 & 0.968 & 0.709 & 0.9558 & 0.9174 & 0.764 \\
\hline F10 & 0.972 & 0.805 & 0.960 & 0.9073 & 0.773 \\
\hline F11 & 0.9614 & 0.785 & 0.901 & 0.892 & 0.777 \\
\hline F12 & 0.9457 & 0.752 & 0.947 & 0.896 & 0.71 \\
\hline F13 & 0.9348 & 0.812 & 0.924 & 0.874 & 0.657 \\
\hline F14 & 0.9225 & 0.855 & 0.937 & 0.896 & 0.701 \\
\hline F15 & 0.970 & 0.845 & 0.916 & 0.875 & 0.711 \\
\hline F16 & 0.9633 & 0.855 & 0.938 & 0.887 & 0.721 \\
\hline F18 & 0.9363 & 0.895 & 0.951 & 0.913 & 0.611 \\
\hline F19 & 0.9358 & 0.894 & 0.936 & 0.908 & 0.632 \\
\hline F20 & 0.9562 & 0.903 & 0.942 & 0.901 & 0.732 \\
\hline F21 & 0.990 & 0.917 & 0.961 & 0.923 & 0.62 \\
\hline Marketed & 0.958 & 0.893 & 0.946 & 0.929 & 0.59 \\
\hline
\end{tabular}

Table 7: Parameters after accelerated stability study of optimized formulation F21

\begin{tabular}{|c|c|c|c|c|}
\hline \multirow[t]{2}{*}{ Parameters } & \multicolumn{4}{|c|}{ Temperature maintained at $40 \pm 2^{\circ} \mathrm{C} \mathrm{RH}$ maintained at $75 \% \pm 5 \% \mathrm{RH}$} \\
\hline & Initial & After 1 month & After 3 months & After 6 months \\
\hline Drug content $(\%)$ & $98.36 \pm 0.68$ & $97.24 \pm 0.65$ & $97.02 \pm 0.65$ & $96.34 \pm 0.62$ \\
\hline In vitro drug release (\%) & $98.67 \pm 5.40$ & $98.21 \pm 5.39$ & $98.02 \pm 5.25$ & $97.36 \pm 5.15$ \\
\hline Floating lag time & 33 & 34 & 35 & 35 \\
\hline
\end{tabular}

RH: Relative humidity

The micromeritic parameters and evaluation parameters such as weight variation, thickness, hardness, friability, and drug content existed were found to be within limits and summarized in Tables 4 and 5, respectively.

\section{In vitro buoyancy study}

All the prepared Ritonavir dosage forms showed floating lag time of $<1$ min and floated in $0.1 \mathrm{~N} \mathrm{HCl}$ intended for additional than $12 \mathrm{~h}$ (Fig. 2). Sodium bicarbonate content controls the floating behavior including the lag time. Increased sodium bicarbonate content caused rapid formation and entrapment of $\mathrm{CO}_{2}$ resulted in reduction floating lag time. Optimized formulation F21 showed minimum floating lag time of $33 \mathrm{~s}$ and total floating time for formulations $>24 \mathrm{~h}$ (Fig 3).

In vitro dissolution studies

From the results, it can be observed that the polymer HPMC K 100M has a controlling effect on release drug from floating matrix tablet of Ritonavir compared to HPMC K15 M and HPMC K 4M. The concentration of polymer was added in increasing order to check its drug release retarding ability, and F21 was considered as best one among the all the formulations, drug release was found to be higher $98.67 \pm 5.40$, when compared with marketed product of $91.46 \pm 5.02$ within 24 h (Figs. 4-6).

\section{Mathematical modeling of optimized formula (F21) of Ritonavir} floating tablets

From the results, it is apparent that the regression coefficient value closer to unity in case of zero-order plot, i.e., 0.990 indicates that drug release follows zero-order mechanism. The drug release mechanism of optimized Ritonavir tablets F21 was best fitting to zero-order and Higuchi model because of the regression coefficient, thus, mechanism of drug release by diffusion. Further, the $n$ value obtained from the Korsmeyer-Peppas plots, i.e., 0.62 indicates non-Fickian (anomalous) transport. Thus, active ingredient is being released by coupled diffusion and erosion. The reference standard (marketed product) regression coefficient value is closer to unity in case of zero-order plot, i.e., 0.958,
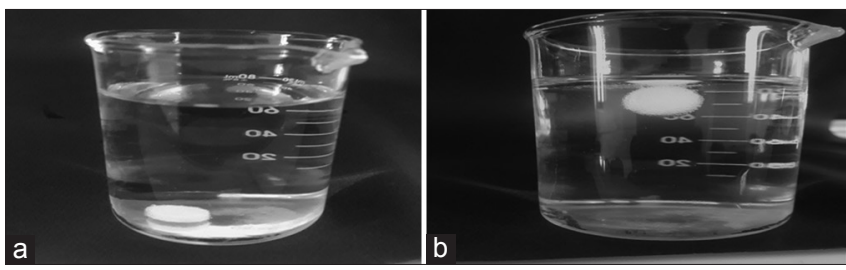

Figure 2: Pictorial representation of floating lag time of Ritonavir optimized formulation (F21). (a) time interval: 0 s. (b) time interval: 33

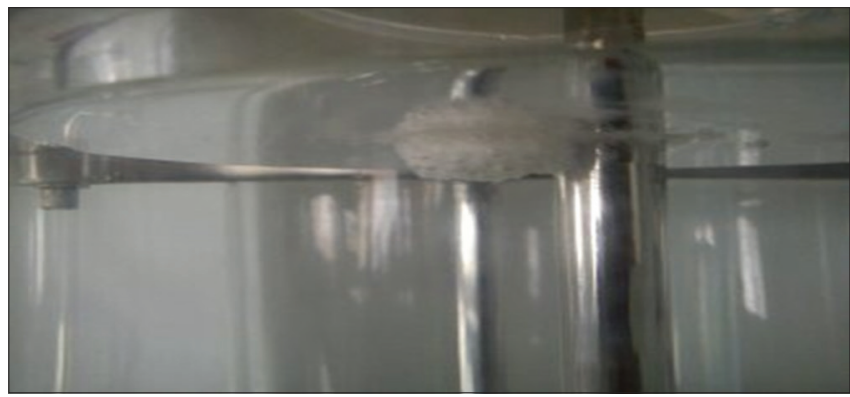

Figure 3: Ritonavir floating tablets after $24 \mathrm{~h}$

specifying that drug release follows zero-order mechanism. These data indicate lesser amount linearity once plotted by the first-order equation. Hence, it can be concluded that, in case of marketed product also, the major mechanism of drug release follows zero-order kinetics. However, the linearity of the optimized formulation is more when compared to a marketed product. Results are summarized in Table 6 and graphs are depicted in Fig. 7-14. 


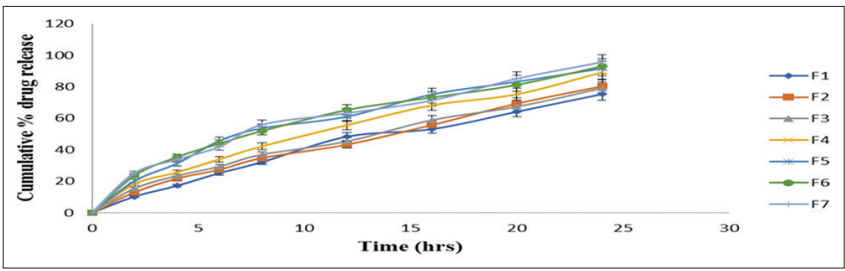

Figure 4: In vitro drug release profile of Ritonavir floating tablets F1-F7

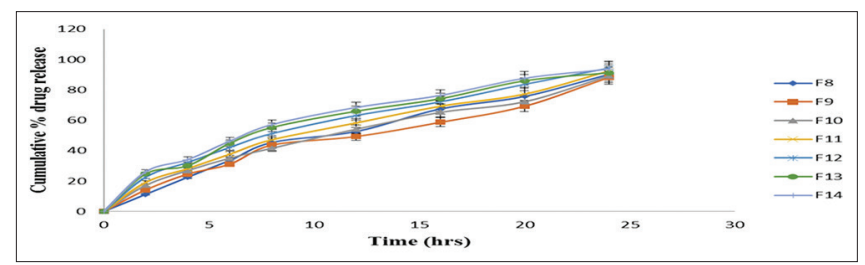

Figure 5: In vitro drug release profile of Ritonavir floating tablets F8-F14

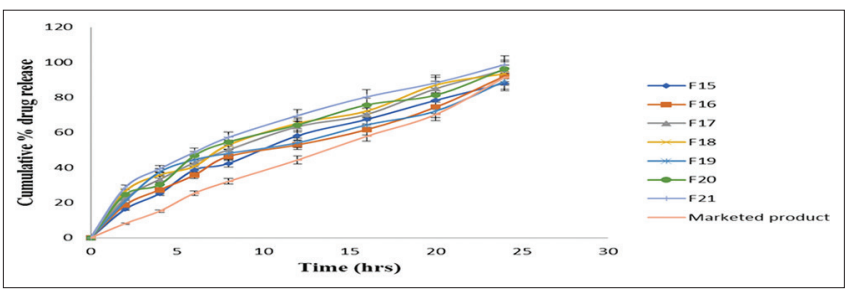

Figure 6: In vitro drug release profile of Ritonavir floating tablets F15-F21

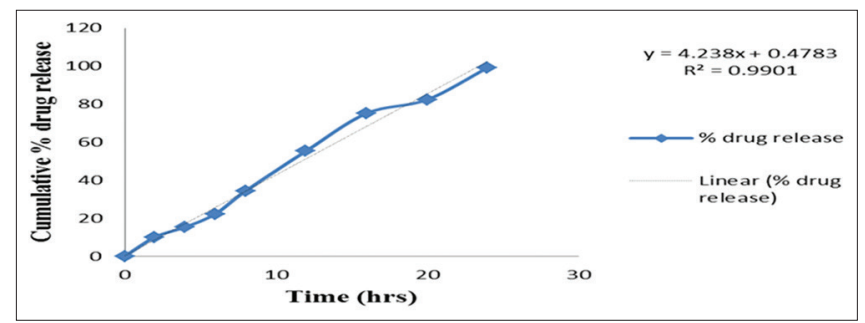

Figure 7: Zero-order plots for the optimized formulation (F21)

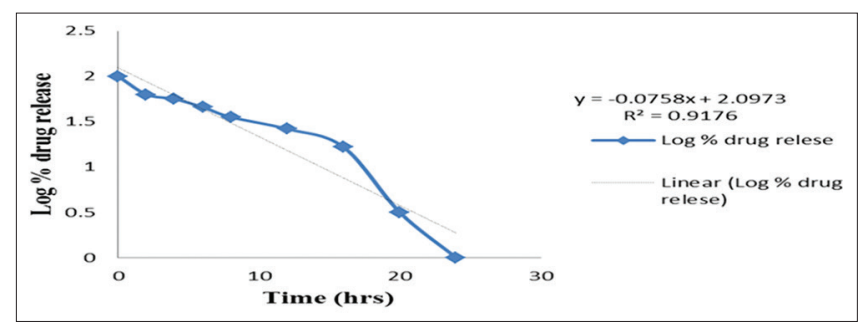

Figure 8: First-order plots for the optimized formulation (F21)

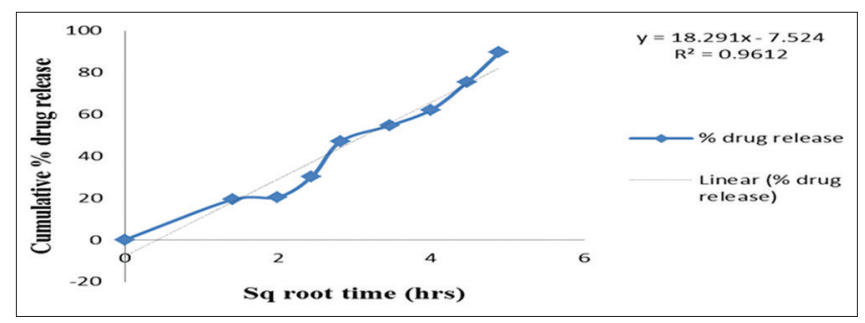

Figure 9: Higuchi plots for the optimized formulation (F21)

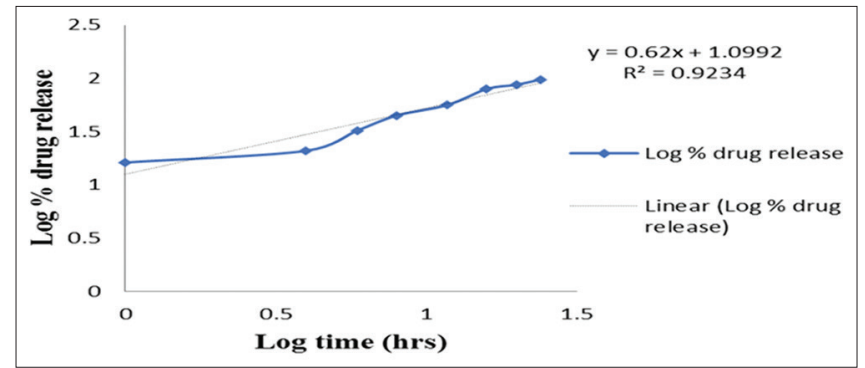

Figure 10: Korsmeyer-Peppas plots for the optimized formulation (F21). In vitro drug release order kinetics for marketed product

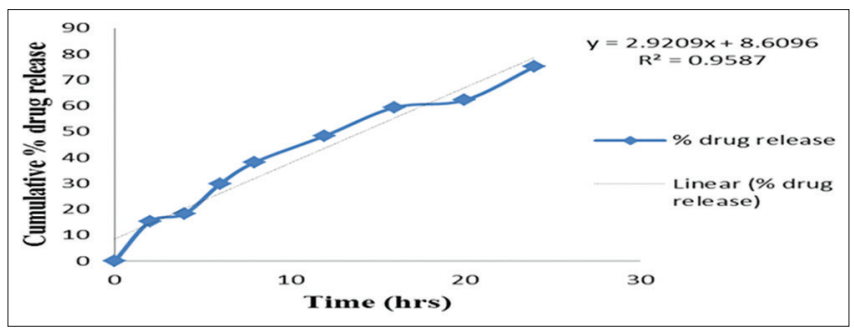

Figure 11: Zero-order plots for the marketed product

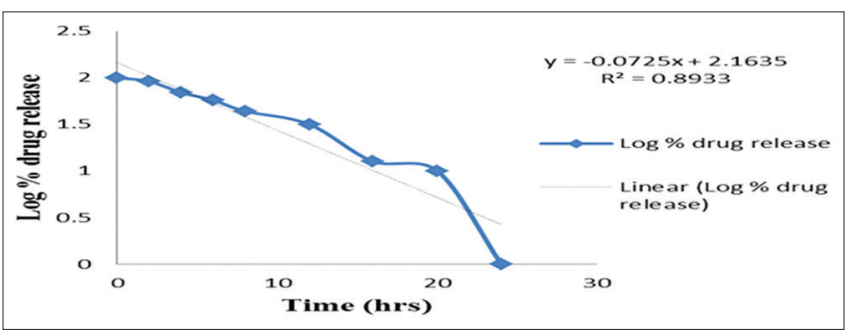

Figure 12: First-order plot for the marketed product

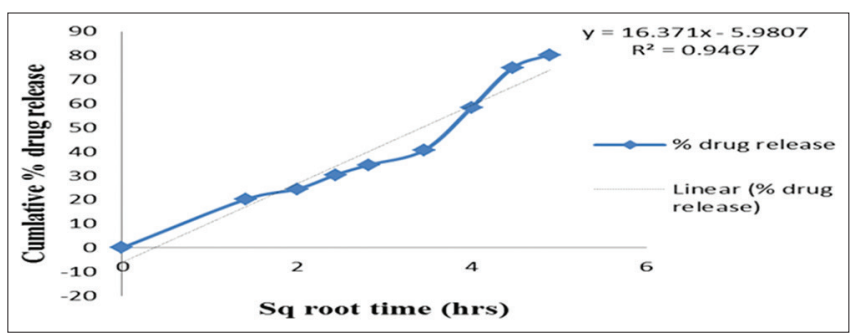

Figure 13: Higuchi plot for the marketed formulation

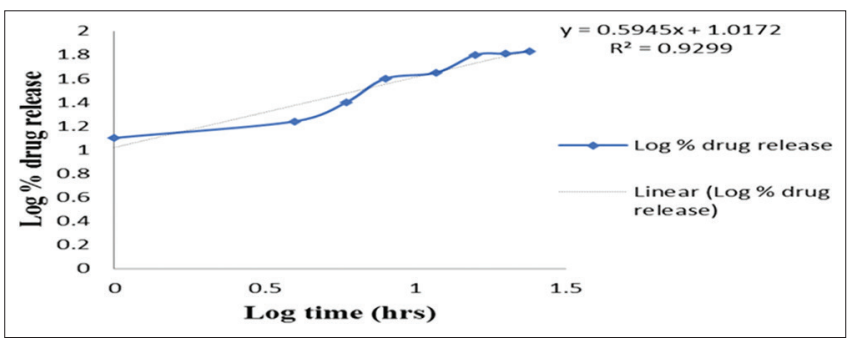

Figure 14: Korsmeyer-Peppas plot for the marketed product

Drug-excipient compatibility studies

There is no alteration in the peaks of Ritonavir pure drug and optimized formulation, suggesting that there was no interaction takes place between drug and excipients and the spectrums are depicted in Figs. 15-17. 


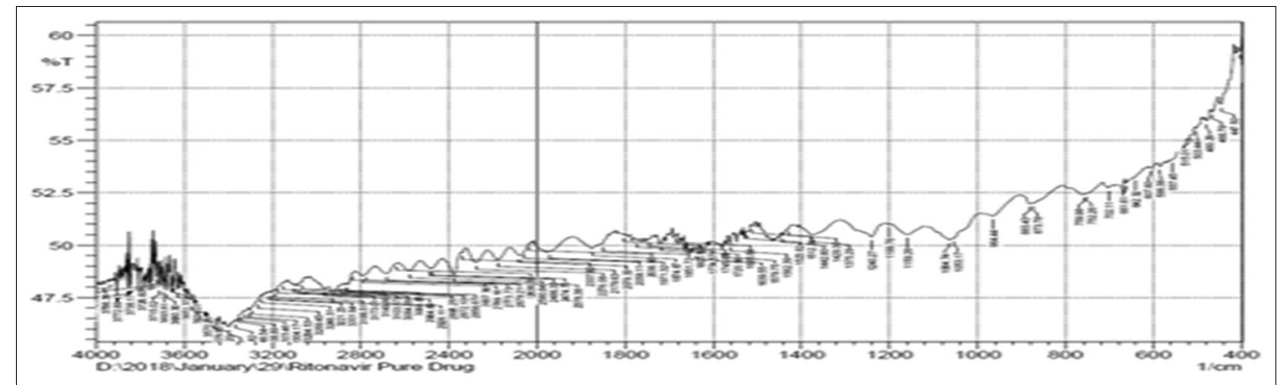

Figure 15: Fourier-transform infrared spectroscopy of pure drug Ritonavir

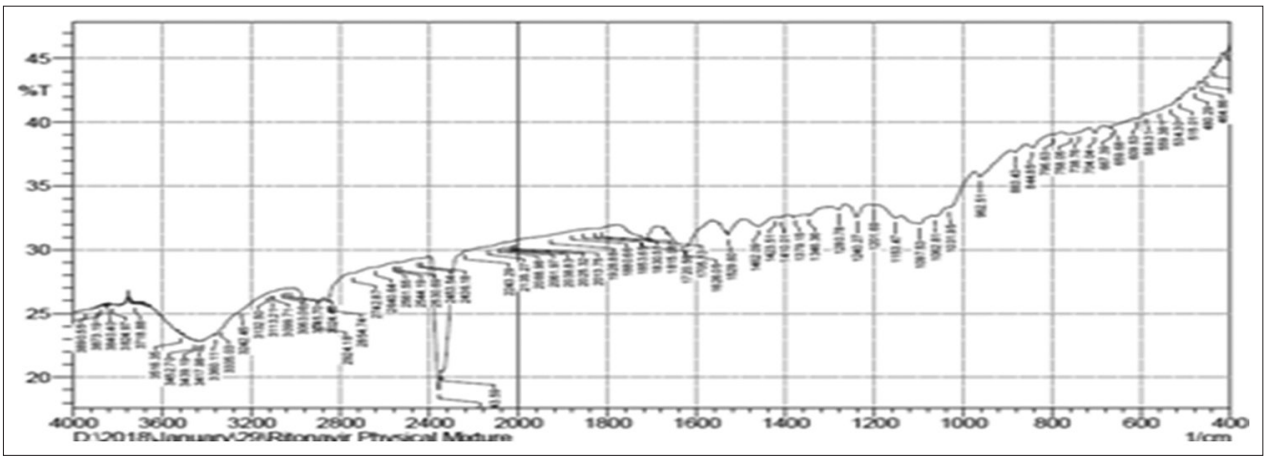

Figure 16: Fourier-transform infrared spectroscopy of Ritonavir physical mixture

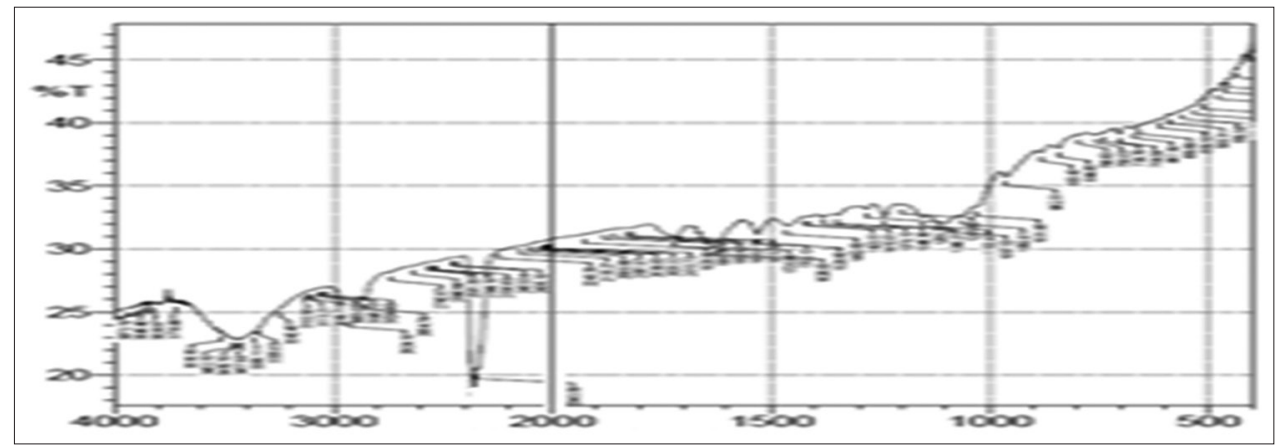

Figure 17: Fourier-transform infrared spectroscopy of Ritonavir optimized formulation

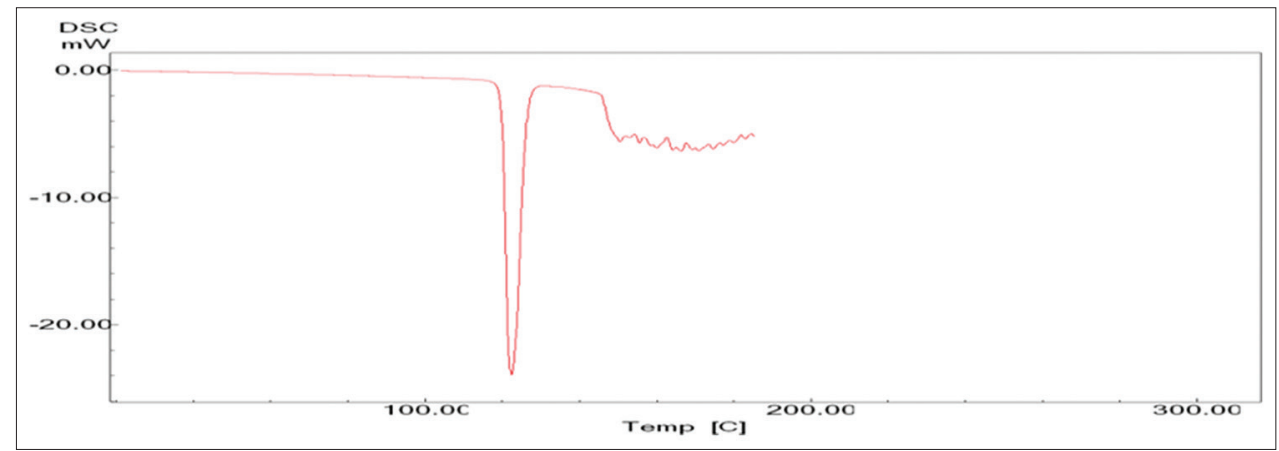

Figure 18: Differential scanning calorimetry thermogram of Ritonavir pure drug

\section{DSC studies}

Pure powdered Ritonavir showed melting endotherm at $122.10^{\circ} \mathrm{C}$. DSC thermogram of floating tablet showed melting peak drug at $119.36^{\circ} \mathrm{C}$. There was no significant difference in melting point of drug and optimized formulation. It is compatible with excipients present in the tablet and there was no major interaction of the drug with the excipients; it is depicted in Figs. 18-21.

\section{SEM studies of Ritonavir floating tablets}

The SEM of optimized floating tablet shows a rough surface morphology and dented surface structure, but they showed good floating ability on medium, indicating that intact surface it is shown in Fig. 22. The shell of tablet also showed some porous structure and it may be due to the release of carbon dioxide. 


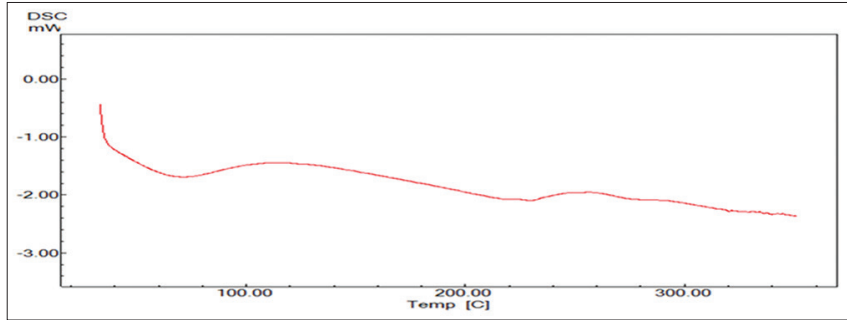

Figure 19: Differential scanning calorimetry thermogram of hydroxypropyl methylcellulose K15M

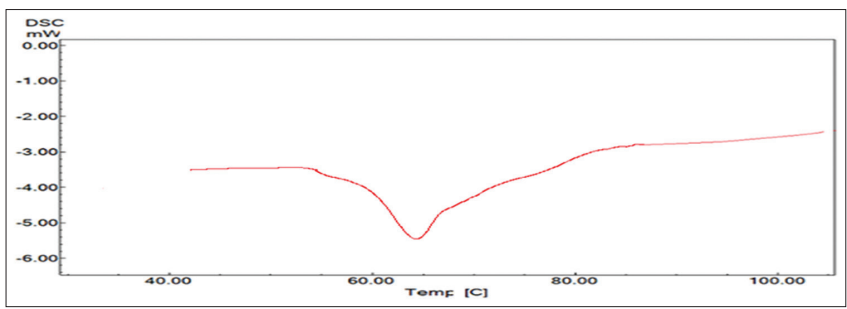

Figure 20: Differential scanning calorimetry thermogram of WSR 303

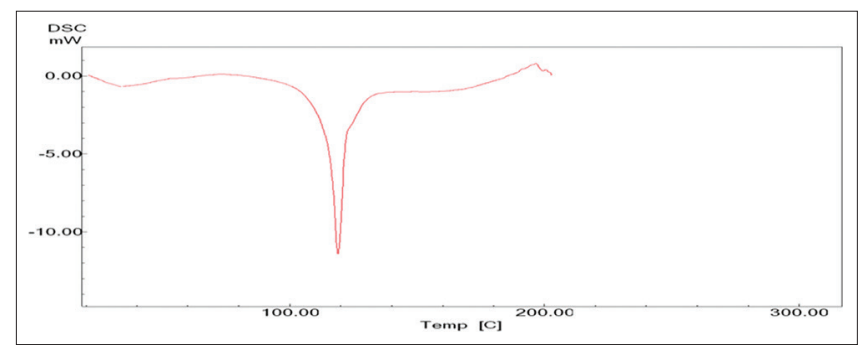

Figure 21: Differential scanning calorimetry thermogram of optimized formulation

Stability studies

There were no changes observed in percentage drug content, in vitro drug release studies, and floating lag time during storage of the optimized formulation, and the results are tabulated in Table 7. Hence, the optimized formulation was found to be stable.

In vivo radiographic studies of Ritonavir optimized formulation (F21) The behavior of the tablet in the dog stomach was observed in real time using a radiographic imaging technique. On radiographic images made $0.5 \mathrm{~h}$ after the administration, the tablets were observed in the animal's stomach. In the next picture taken at $1.5 \mathrm{~h}$, significant changes were detected, and the tablet had altered its position and turned around. This provided evidence that the tablets did not adhere to the gastric mucus but, on the contrary, floated on the gastric fluid. In addition, the swelling of the tablet is visualized very well together with the white dry core and translucent swelling layer around it. As the swelling continued, the results have shown, in Fig. 23, that the mean gastric residence time for the developed floating tablets was $330 \min \pm 40$. The comparison of gastric motility and stomach emptying between humans and dogs shows no big differences. Therefore, it might be speculated that experimentally proven increased GRT in beagle dogs can be compared to known literature data for humans.

\section{CONCLUSION}

In the present work, it can be concluded that the Ritonavir floating tablets can be an innovative and promising approach for the delivery and the treatment of HIV. The optimized formulation F21 contains HPMC K100M, Polyox WSR 303, and gas generating agent. In vitro release profile of Ritonavir and marketed product when compared
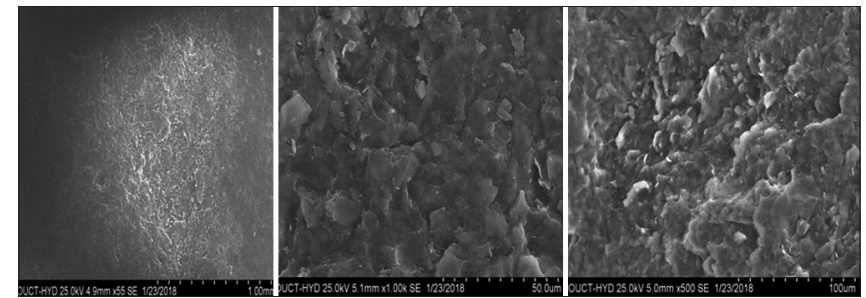

Figure 22: Scanning electron micrographs of optimized Ritonavir floating matrix tablets
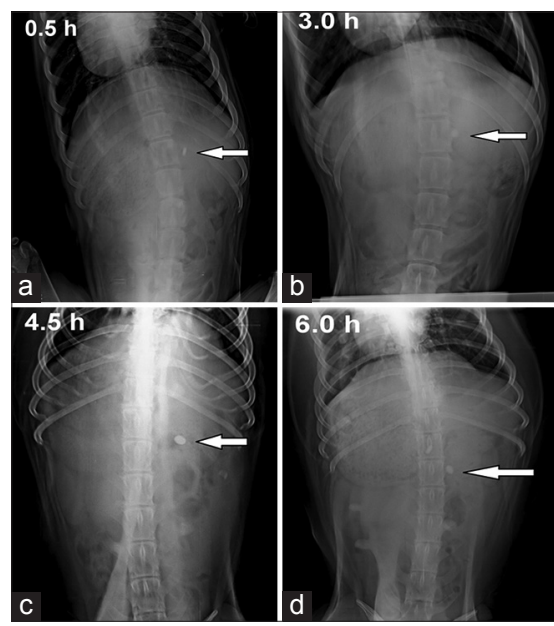

Figure 23: Intragastric behavior of the $\mathrm{BaSO}_{4}$-loaded optimized Ritonavir floating tablets (F21) represented by typical radiographic images after definite time intervals (The tablet is pointed by arrow). (a) after $0.5 \mathrm{~h}$ (b) after $3 \mathrm{~h}$ (c) after $4.5 \mathrm{~h}$, and (d) after $6 \mathrm{~h}$ of tablet administration

the optimized formulation F21 showed drug release of $98.67 \pm 5.40 \%$, whereas $91.46 \pm 5.02 \%$ of the drug was released from the marketed product within $24 \mathrm{~h}$. The major mechanism of drug release follows zero-order kinetics and non-Fickian transport by coupled diffusion and erosion. This means that water diffusion and the polymer rearrangement have an essential role in the drug release. The release rate constant of optimized formulation F21 was low enough prolonging drug delivery. In vivo experiments supported the expectations in prolonging the gastric residence time in the fasted state in beagle dogs. The mean gastric residence time for the tested tablets was $330 \mathrm{~min} \pm 40$. This result is encouraging because a longer gastric residence time is an important condition for higher bioavailability of the drugs included in the prolonged or controlled release dosage form.

\section{AUTHORS' CONTRIBUTIONS}

R. Shireesh Kiran: Drafted the complete manuscript. B. Chandra Shekar: Supervisor of the research work, provided the guidance in the research work. B. Nagendra Babu: Advised the scholar to get quality of work.

\section{CONFLICTS OF INTEREST}

No conflicts of interest were raised by the authors.

\section{REFERENCES}

1. Whitehead JT, Collett JH. Development of a gastroretentive dosage form. Eur J Pharm Sci 1996;4:182.

2. Emara LH, Abdou AR, El-ashmawy AA, Mursi NM. Preparation and evaluation of metronidazole sustained release floating tablets. Int $\mathrm{J}$ Pharm Pharm Sci 2014;6:198-204

3. Mojaverian P, Vlasses PH, Kellner PE, Rocci ML Jr. Effects of gender, posture, and age on gastric residence time of an indigestible solid: Pharmaceutical considerations. Pharm Res 1988;5:639-44. 
4. Deshpande AA, Rhodes CT, Shah NH. Controlled release drug delivery system for prolonged gastric residence. Drug Dev Ind Pharm 1996;22:531-9.

5. Sawant K, Patel M, Patel J, Mundada P. Formulation, optimization, characterization and in vivo anti-ulcer activity of esomeprazole magnesium trihydrate gastro-resistant microspheres. Int J Pharm Pharm Sci 2014;6:198-204.

6. Hwang SK, Park H, Park K. Gastric retentive drug delivery systems. Crit Rev Ther Drug Carrier Syst 1998;15:243-84.

7. Gruber P, Rubinstein A, Li VH, Bass P, Robinson JR. Gastric emptying of nondigestible solids in the fasted dog. J Pharm Sci 1987;76:117-22.

8. Desai S, Bolton S. A floating controlled-release drug delivery system: In vitro-in vivo evaluation. Pharm Res 1993;10:1321-5.

9. Li S, Lin S, Chien YW, Daggy BP, Mirchandani HL. Statistical optimization of gastric floating system for oral controlled delivery of calcium. AAPS PharmSciTech 2001;2:E1.

10. Li S, Lin S, Daggy BP, Mirchandani HL, Chien YW. Effect of formulation variables on the floating properties of gastric floating drug delivery system. Drug Dev Ind Pharm 2002;28:783-93

11. Sweetman SC. Martindale: The Complete Drug Reference. $35^{\text {th }}$ ed. London: Pharmaceutical Press; 2007. p. 766-79.

12. Rao TR, Krishna KB, Hussain MA, Anjum M, Azizurrahman M. Formulation and evaluation of gastroretentive floating tablets of quetiapine fumarate. Res J Pharm Biol Chem Sci 2014;5:975-8585.

13. Nasrin N, Asaduzzaman M, Rumana M, Rizwan F, Alam A. A comparative study of physical parameters of selected ketorolac tromethamine tablets available in the pharma market of Bangladesh. J Appl Pharm Sci 2008;1:101-3.
14. Penners G, Lustig K, Jorg PVG. Expandable pharmaceutical forms. US Patent No. 5; 1997. p. 651-985.

15. Phuapradit W, Bolton S. Influence of tablet density on oral absorption of sustained release acetaminophen matrix tablets. Drug Dev Ind Pharm 1991; 17:1097-107.

16. Phuapradit W. Influence of Tablet Buoyancy on Oral Absorption of Sustained Release Acetaminophen Matrix Tablets. Jamaica: St John's University; 1989.

17. Małgorzata W, Marcin Z, Aleksandra A. Tasting cetirizine-based microspheres with an electronic tongue. Sens Actuators B Chem 2016;238:1190-8.

18. Janssen M, Timur UT, Woike N, Welting TJ, Draaisma G, Gijbels M, et al. Celecoxib-loaded PEA microspheres as an auto regulatory drug-delivery system after intra-articular injection. J Control Release 2016;244:30-40

19. Kumar TL, Lal KM. Stability study and in-vivo evaluation of lornoxicam loaded ethyl cellulose microspheres. Int J Pharm Sci Drug Res 2014;6:26-30.

20. Singh K, Kumar A, Langyan N, Ahuja M. Evaluation of Mimosa pudica seed mucilage as sustained-release excipient. AAPS PharmSciTech 2009; 10:1121-7.

21. Baumgartner S, Kristl J, Vrecer F, Vodopivec P, Zorko B. Optimisation of floating matrix tablets and evaluation of their gastric residence time. Int J Pharm 2000;195:125-35.

22. Siepmann J, Kranz H, Bodmeier R, Peppas NA. HPMC-matrices for controlled drug delivery: A new model combining diffusion, swelling, and dissolution mechanisms and predicting the release kinetics. Pharm Res 1999;16:1748-56. 